\title{
CONSTRUIR E RECORDAR O PASSADO: A FORMAÇÃO TERRITORIAL DA COROA DE ARAGÃO INTERPRETADA POR PEDRO O CERIMONIOSO
}

(1336-1387)

\author{
TO CONSTRUCT AND REMEMBER THE PAST: THE \\ TERRITORIAL FORMATION OF THE CROWN OF \\ ARAGON INTERPRETED BY PETER III (1336-1387)
}

Luciano José Vianna*

Resumo: Na escrita da história, diversas vezes o mesmo passado foi relembrado em diferentes contextos, de forma que diversos manuscritos que contêm o mesmo texto constituem a tradição manuscrita de um documento, a qual pode apresentar diferenças textuais, paleográficas e codicológicas entre si e, principalmente, diferentes motivos de composição. Neste sentido, objetivo deste artigo é analisar os diferentes contextos de composição dos manuscritos do Livro dos Feitos de Jaime I de Aragão (1208-1276) produzidos durante o reinado de Pedro III de Aragão (1336-1387), também conhecido como Pedro o Cerimonioso: o primeiro no ano de 1343 (ms. 1 da Biblioteca de la Universitat de Barcelona) e o segundo no ano de 1380 (ms. 1734 da Biblioteca de Catalunya). Nossa intenção é reconstruir os contextos de composição destes manuscritos para compreender como a construção e a recordação do passado por parte do rei Pedro o Cerimonioso afetou a formação territorial da Coroa de Aragão.

Palavras-chave: Livro dos Feitos. Tradição manuscrita. Jaime I de Aragão. Pedro III de Aragão. Formação territorial da Coroa de Aragão.

\footnotetext{
* Doutorando no Programa Cultures en Contacte a la Mediterrània do Departament de Ciències de l'Antiguitat i de l'Edat Mitjana da Universitat Autònoma de Barcelona. Orientadores: Prof. Dr. Alexander Martin Fidora Riera (ICREA-UAB-IEM) e Prof. Dr. José Enrique Ruiz-Domènec (UAB-IEM). Bolsista do Programa Personal Investigador Novell da Direcció General de Recerca (FI-DGR 2011) da Agència de Gestió d'Ajuts i de Recerca (AGAUR).E-mail: lucianojvianna@ig.com.br
} 


\begin{abstract}
In the writing of history, several times the same past was remembered in different contexts, so that several manuscripts that contain the same text constitute the manuscript tradition of a document, which may present textual, palaeographical and codicological differences and, mainly, different reasons for its composition. In this sense, this article aims to analyze the different contexts of composition of the manuscripts of the Book of Deeds of James I of Aragon (1208-1276) produced during the reign of Peter III of Aragon (1336-1387), also known as Peter the Ceremonious: the first manuscript was produced in the year 1343 (ms. 1 of the Library of the Universitat de Barcelona) and the second in 1380 (ms. 1734 of the Library of Catalunya). Our intention is to reconstruct the contexts of compositions of these manuscripts in order to understand how the elaboration and recordation of the past by Peter III influenced the territorial formation of the Crown of Aragon.
\end{abstract}

Keywords: Book of Deeds. Manuscript Tradition. James I of Aragon. Peter III of Aragon. Territorial formation of the Crown of Aragon.

\title{
INTRODUÇÃO
}

Muitas vezes, os diversos textos de uma tradição manuscrita apresentam diferentes informações paleográficas, codicológicas e textuais, e, portanto, quando são estudados separadamente a singularidade de cada códice é notável. Em nosso caso, quando analisamos os diversos manuscritos do Livro dos Feitos, obra que contém a vida e os feitos de Jaime I o Conquistador, estas peculiaridades fazem de cada manuscrito um partícipe único nesta tradição possuindo diferentes características. Encontrando a singularidade de cada manuscrito, ou seja, contextualizando-os, podemos encontrar o motivo destes retornos ao passado:

What is important here is to recognize the fruitfulness of the medieval approach to the past. Precisely because it was so little known, in any critical sense, the past could become a vehicle for change. All that was needed was to recreate it in the image of the present, and then claim its authority for the legitimation of contemporary practices. ${ }^{1}$

Devemos reconhecer o significado do retorno ao passado realizado pelos medievais nos momentos em que o necessitavam ${ }^{2}$, de forma que os exemplos pretéritos eram utilizados em contextos específicos no presente. Neste sentido, podemos afirmar que um dos motivos pelos quais ocorria o processo de transmissão textual de uma determinada obra era pelas necessidades políticas dos patrocinadores das mesmas ${ }^{3}$, as quais muitas vezes serviam como um locus para articular os problemas e intenções contemporâneas: 
Ya no se trata tanto de distinguir lo verdadero de lo falso en los textos históricos medievales, de localizar los pasajes espurios de las crónicas, como de analizar las relaciones entre el texto y el contexto. Se parte de la idea de que esas narraciones tienen una intencionalidad concreta. Se tiene en cuenta que la literatura de ficción prolifera en las sociedades sin excesivas necesidades de justificación y, en cambio, los textos históricos abundan en las sociedades problematizadas, que precisamente buscan consolidarse a través de la aprehensión de un pasado remoto glorioso. Se huye de una lectura ingenuamente racionalista y positivista de las crónicas, buscando una interpretación que tenga en cuenta sus simbologías, sus mitos, sus medias verdades y sus elocuentes silencios. ${ }^{4}$

Assim, refazer o caminho de um texto com todos os seus exemplares nos permite estudar os contextos nos quais cada manuscrito fora composto e principalmente observar e nos aproximar das verdadeiras intenções do ato historiográfico. Como cada versão de um texto tem a sua própria vida, sua própria história e suas características particulares ${ }^{5}$ para compreendê-la como objeto único devemos observar suas variantes textuais, as características paleográficas e codicológicas, as quais foram determinadas ou pelo copista, ou pelo tradutor, ou ordenadas pelo patrocinador do texto influenciado (ou não) pelo seu contexto histórico. ${ }^{6}$ Seguir estes procedimentos auxilia na identificação do comportamento político cultural no qual o texto composto estava inserido. ${ }^{7}$ Portanto, analisar a transmissão manuscrita de uma obra significa reconstruir o tempo, o espaço e as condições em que a mesma fora produzida. ${ }^{8}$

\section{O LIVRO DOS FEITOS E SUA TRADIÇÃO MANUSCRITA}

O Livro dos Feitos do rei Jaime I, a primeira obra das chamadas Quatro Grandes Crônicas, ${ }^{9}$ possui uma dupla tradição manuscrita: em catalão (Llibre dels Fets) e em latim (Liber Gestorum). Ademais o texto conta com diversas edições, sendo que as principais são a de Ferran Soldevila ${ }^{10}$, a de Jordi Bruguera $^{11}$ - estas duas catalãs - e a de Martínez San Pedro ${ }^{12}$ - esta latina. 
Tabela 1 - Manuscritos da tradição do Llibre dels Fets

\begin{tabular}{ccc}
\hline Manuscritos & Localizacão & Data \\
\hline ms. 1 & Biblioteca de la Universitat de Barcelona & 1343 \\
ms. 1734 & Biblioteca de Catalunya & 1380 \\
ms. Y-III-5 & Biblioteca del Monasterio del Escorial & - \\
ms. II-475 & Biblioteca del Palacio Real de Madrid & - \\
ms. 10121 & Biblioteca Nacional de España & - \\
ms. 9-4769 & Biblioteca de la Real Academia de la Historia de Madrid & - \\
ms. 15398 & Biblioteca Nacional de España & 1557 \\
ms. 10-VI-23 & Biblioteca de Catalunya & 1515 \\
ms. 69 & Biblioteca de la Universitat de Barcelona & 1619 \\
ms. $41 / 90$ & Arxiu de la Corona d'Aragó & - \\
ms. 893 & Biblioteca Nacional de España & s. XVII \\
ms. HC411/166 & Hispanic Society of America & s. XVII \\
ms. 2251 & Biblioteca de Catalunya & s. XVIII \\
ms. 13208 & Biblioteca Nacional de España & 1779 \\
\hline Fonte: Tabela sistematizada a partir das informações encontradas em BRUGUERA.
\end{tabular}

Tabela 2 - Manuscritos do Liber Gestorum

\begin{tabular}{ccc}
\hline Manuscritos & Localização & Data \\
\hline ms. 64 & Biblioteca de la Universitat de Barcelona & 1313 \\
ms. 40 & Arxiu Històric de Mallorca & s. XIV \\
ms. 6 & Arxiu de la Catedral de Palma de Mallorca & s. XIV \\
ms. 1018 & Biblioteca Central de Barcelona & s. XVI \\
ms. 41 & Arxiu de la Corona d'Aragó & s. XVII \\
ms. $9-4565$ & Real Academia de la Historia & s. XIX \\
\hline Fonte: Tabela sistematizada a partir das informações encontradas em MARTíNEZ SAN \\
PEDRO. ${ }^{14}$
\end{tabular}

Os dois primeiros manuscritos da tradição catalã foram compostos durante o reinado de Pedro o Cerimonioso, respectivamente nos anos de 1343 e 1380. O reinado deste rei localiza-se no século XIV, centúria decisiva para a situação política, cultural e linguística da Europa, período durante o qual se desenvolveram as instituições sociais e políticas dos territórios ${ }^{15}$, principalmente no que se refere à organização dos estados e à formação de grupos intelectuais. ${ }^{16}$ Dentro deste contexto o reinado de Pedro o Cerimonioso apresenta um desenvolvimento distinto dos seus antepassados em relação à produção textual, principalmente no que se refere à produção de testemunhos autógrafos; este monarca incluiu a escrita em sua ação de governo e utilizou-a como ferramenta para transmitir ordens e organizar suas tarefas políticas cotidianas. ${ }^{17}$ Esta característica foi tão presente em seu governo que alguns 
autores acreditam que durante o período final do medievo não existiu um monarca tão consciente da necessidade de governar através do ato de escrever. ${ }^{18}$

Ademais, o rei Pedro o Cerimonioso apresentava um interesse notável pelo saber de seu tempo e principalmente pela memória histórica, e neste sentido empreendeu uma política de produção escrita não somente relacionada à história universal, mas também com sua história particular ${ }^{19}$ e dos seus antepassados, apresentando uma verdadeira vocação para este empreendimento. ${ }^{20}$ Seguramente o Cerimonioso foi consciente desde o começo de seu reinado da importância que a documentação escrita tinha para as suas decisões políticas, consideração que provavelmente foi fruto da sua formação antes de converter-se em monarca. ${ }^{21}$

Devido a sua personalidade, sua chancelaria tornou-se um centro significativo de produção e de cópia de manuscritos. ${ }^{22}$ Neste sentido, podemos falar da existência de um scriptorium em seu reinado ${ }^{23}$, o qual fora muito importante para a comunicação escrita em seu governo. ${ }^{24}$ Durante o seu reinado, a chancelaria adquiriu contornos administrativos mais precisos, apresentando uma estrutura mais organizada em comparação com a época de seus antepassados. ${ }^{25}$ Além disso, a intervenção do monarca no processo de composição das obras foi considerável, pois o mesmo não somente solicitava o texto para copiar e indicava o suporte no qual deveria ser realizado, mas também intervinha no processo de produção dos exemplares ${ }^{26}$, como fizera com a sua Crônica ${ }^{27}$ e também com os dois primeiros exemplares da tradição manuscrita do Livro dos Feitos: o ms. 1 da Biblioteca da Universitat de Barcelona e o ms. 1734 da Biblioteca de Catalunya.

\section{O MS. 1 DA BIBLIOTECA DA UNIVERSITAT DE BARCELONA ${ }^{28}$}

A obra mais importante produzida durante o reinado do Cerimonioso foi sem dúvida a sua Crônica. Em suas páginas encontram-se os principais acontecimentos de seu reinado e o mais importante realizado pelo monarca: a confiscação da Coroa de Maiorca. ${ }^{29}$ Entretanto, até o ano de 1343, ano da reincorporação da Coroa de Maiorca à Coroa de Aragão, é correto afirmar que a obra mais importante composta sob os auspícios deste monarca fora a cópia do livro das memórias de seu tataravô.

Algumas informações ajudam a reconstruir o contexto de composição deste manuscrito. Em primeiro lugar há um documento em que Pedro o Cerimonioso solicita ao abade de Poblet, Pons de Copons (1316-1348), este códice. ${ }^{30}$ Ademais, seu colofão apresenta o contexto específico de sua composição. ${ }^{31}$ Finalmente o último documento que faz referência a este manuscrito é a Crônica de Pedro o Cerimonioso, na qual o rei afirma que estava com este livro em suas mãos no dia 21 de novembro de $1344 .{ }^{32}$ 
Considerando a data dos dois primeiros documentos apresentados (ou seja, o ano de 1343), os quais foram compostos no ano de produção deste códice, quais seriam as razões para o Cerimonioso solicitar este livro no contexto da reincorporação da Coroa de Maiorca à Coroa de Aragão? Seria somente um ato de manutenção material, já que utilizou no primeiro documento o verbo "rescribi" (reescrever) do papiro para o pergaminho, manutenção também utilizada em outros documentos durante seu reinado? ${ }^{33}$ Ou seria um ato de manutenção da memória histórica de seu tataravô, o qual conquistara e governara os reinos que formavam parte da Coroa de Aragão? Ou esta solicitação teria um significado histórico muito específico o qual somente compreenderíamos (re)construindo o contexto de composição do manuscrito, ou seja, o ano de 1343? Como desejamos descobrir o motivo de sua produção, devemos reportar-nos ao seu contexto de composição e refazê-lo para compreender a provável função deste códice.

Tabela 3 - Condes de Barcelona como Reis de Aragão

\begin{tabular}{cc}
\hline Período do reinado & Condes de Barcelona e Reis de Aragão \\
\hline $1131-1162$ & Raimundo Berengário o Santo ${ }^{34}$ \\
$1162-1196$ & Afonso o Casto \\
$1196-1213$ & Pedro o Católico \\
$1213-1276$ & Jaime o Conquistador \\
$1276-1285$ & Pedro o Grande \\
$1285-1291$ & Afonso o Liberal \\
$1291-1327$ & Jaime o Justo \\
$1327-1336$ & Afonso o Benigno \\
$1336-1387$ & Pedro o Cerimonioso \\
$1387-1396$ & João o Caçador \\
$1396-1410$ & Martinho o Humano \\
\hline
\end{tabular}

Fonte: Tabela sistematizada a partir das informações encontradas em AURELL ${ }^{35}$, BALCELLS $^{36}$ e RUCQUOI. ${ }^{37}$

Como os dois manuscritos que são objetos de análise neste artigo foram compostos sob as ordens de Pedro o Cerimonioso, e como necessitamos adentrar os seus contextos de composição, analisaremos sua Crônica para que possamos nos aproximar aos seus pensamentos sobre os contextos de composição dos manuscritos. De acordo com Gabrielle M. Spiegel, compreender o pensamento dos patrocinadores das obras é essencial para ajudar a entender os seus motivos de composição. ${ }^{38}$

Ao analisar a Crônica de Pedro o Cerimonioso observamos a insistência deste rei em tratar do assunto sobre a confiscação da Coroa de Maiorca nos três primeiros capítulos de sua obra. ${ }^{39}$ Além disso, o terceiro capítulo desta obra retrata os acontecimentos ocorridos entre os reis Coroa de Aragão e de 
Maiorca desde a criação desta Coroa com a morte de Jaime I o Conquistador em 1276 até sua reincorporação definitiva em 1343 por Pedro o Cerimonioso. ${ }^{40}$

Analisando o contexto de produção do manuscrito de Poblet, devemos ressaltar que o Cerimonioso não necessitava conquistar a Coroa de Maiorca, mas sim confiscá-la. Diante desta informação sua Crônica revive todos os acontecimentos entre os reis das duas coroas reformulando-os a partir de sua perspectiva. Seguindo este pensamento, não fora casualidade que o rei documentara a política dos reis da Coroa de Aragão em relação aos reis de Maiorca já no começo de sua Crônica. Por exemplo, ao analisá-la observamos que a principal reclamação por parte de Pedro o Grande refere-se ao fato de que as terras herdadas pelo seu irmão, o rei Jaime II de Maiorca, retiravam grande parte do patrimônio da Coroa de Aragão. ${ }^{41}$ Entretanto, sabemos que as terras que Jaime II de Maiorca herdara eram uma parte muito pequena em comparação com as de seu irmão.

Tabela 4 - Reis de Aragão x Reis de Maiorca entre os anos de 1276 e 1349

\begin{tabular}{cc}
\hline Reis de Aragão & Reis de Maiorca \\
\hline Pedro o Grande $(1276-1285)$ & Jaime II de Maiorca (1276-1311) \\
Afonso o Liberal $(1285-1291)$ & Sancho I de Maiorca (1311-1324) \\
Jaime o Justo $(1291-1327)$ & Jaime III de Maiorca (1324-1349) \\
Afonso o Benigno $(1327-1336)$ & \\
Pedro o Cerimonioso (1336-1387) &
\end{tabular}

Fonte: Dados sistematizados a partir da leitura de MARTÍNEZ FERRANDO. ${ }^{42}$

Diante disso, Pedro o Grande neutralizou as intenções de alianças políticas feitas pelo rei de Maiorca resultando na assinatura do Tratado de enfeudação de Perpinyà, estabelecido em 1279, o qual equivalia a uma anulação do testamento de Jaime I. Depois disso, Jaime II de Maiorca interrompeu os pactos com seu irmão e este preparou a invasão à ilha de Maiorca, a qual fora realizada por seu filho, Afonso o Liberal (1285-1291). Tal fato terminou com a assinatura de outro tratado conhecido como Tratado de Agnani, o qual estabelecia o retorno da coroa maiorquina a Jaime II com a condição de que este rei e seus sucessores reconhecessem o pacto de vassalagem estabelecido com o rei da Coroa de Aragão. ${ }^{43}$ A partir deste momento, os reis de Maiorca seriam vassalos dos reis da Coroa de Aragão e teriam que seguir todas as disposições que o acordo estabelecia: poderiam ter e possuir o reino, porém deveriam permanecer como vassalos, homens próprios e lígios do rei de Aragão. Além disso, deveriam seguir uma última obrigação: participarem das Cortes de Catalunha sempre que fossem convocados. Devemos recordar que no contexto de composição do manuscrito de Poblet (1343) Pedro o Cerimonioso também exigira esta obrigação de Jaime III de Maiorca e, diante de sua recusa, decidira reincorporar a coroa insular a sua Coroa. ${ }^{44}$ 
Estes detalhes encontrados na Crônica de Pedro o Cerimonioso e também nos tratados estabelecidos entre os reis das coroas de Aragão e Maiorca nos direcionam à questão do testamento de Jaime I e à divisão das terras da Coroa entre seus filhos. No caso de Jaime I, seus testamentos sempre foram elaborados de acordo com o nascimento de seus filhos; o último e definitivo fora pronunciado em 26 de agosto de 1272, na localidade de Alzira, dividindo seus reinos entre seus filhos Pedro o Grande e Jaime II de Maiorca. Deste testamento nós não possuímos o original, apenas uma cópia de 29 de maio de 1349 (ou seja, produzida durante o reinado do Cerimonioso). De posse destas informações, analisamos o trecho deste documento referente à divisão das terras da Coroa de Aragão:

Dispostos todos estes legados, instituímos o nosso muito estimado filho primogênito, o infante dom Pedro, herdeiro, para depois da nossa morte, dos reinos de Aragão e de Valência; de Ribagorça, de Pallars, do vale do Aran, do condado de Barcelona, da jurisdição que temos sobre o condado de Urgel e sobre outros lugares e terras da Catalunha, e sobre todos os feudos que qualquer tenha e possua e venha a possuir, em nosso nome, nos referidos reinos, terras e lugares. Com inteiro domínio e com todos os direitos e pertences, completamente, em conjunto e particularmente, sobre os reinos, condado de Barcelona, terras e lugares aos quais antes fizemos referência, e que nos correspondam ou venham a nos corresponder respeito a todos eles ou qualquer deles, diante de qualquer pessoa e qualquer lugar, exceto somente os condados e os outros lugares que deixamos para o seu irmão, o nosso filho muito estimado, infante Jaime. Da mesma forma, instituímos o nosso filho o infante dom Jaime, para depois da nossa morte, do reino de Maiorca e das ilhas de Minorca e Ibiza, e dos condados de Rossilhão, Cerdanha e Conflent, e de todos os feudos que o conde de Foix e o conde de Ampúrias e outras pessoas tenham e venham a ter em nosso nome, e de Cotlliure e de Montpelier, com toda a sua jurisdição e todos os castelos, em completo domínio e com todos os direitos e pertences, e de todos os direitos e jurisdição que temos sobre o viscondado de Carlades. E que os ditos filhos nossos tenham os legados antes determinados por direito de instituição, assim de forma mais completa e detalhada está contido nos instrumentos de repartição e divisão de herança que fizemos com eles..$^{45}$

Estas palavras representam o último desejo de Jaime I, o qual dividira os territórios da Coroa de Aragão de acordo com uma concepção extremamente 
pessoal de suas posses, uma divisão não comum em seu contexto. ${ }^{46}$ No documento observamos a seguinte repartição: Pedro o Grande, o primogênito, herdara os reinos de Aragão e Valência, as localidades de Ribagorza e Pallares, o vale do Aran e os condados de Urgel e de Barcelona; para seu filho Jaime, futuro Jaime II de Maiorca, fora designado o reino de Maiorca, juntamente com as ilhas de Minorca e Ibiza, os condados de Rossilhão e Cerdanha, os feudos dos condes de Foix e Ampúrias e o senhorio de Montpelier. Ademais, Jaime I não somente dividira suas terras entre seus filhos, mas também estabelecera que cada um possuísse sua parte de forma independente; ou seja, Pedro e Jaime teriam posses separadas: Pedro não poderia intervir nas terras de Jaime e este também não poderia atuar nas de seu irmão.

Por outro lado, existe outro documento onde o testamento de Jaime I também está presente. Referimo-nos à narrativa do manuscrito de Poblet produzido em 1343. Vejamos quais são informações:

Ditas todas estas palavras, o infante acima dito, como um filho obediente ao pai, recebeu os nossos mandamentos como bons e verdadeiros, e prometeu-nos cumprir tudo isso dito acima. Antes que ele partisse de nós, na presença dele e de todos aqueles que estavam presentes quando foram ditas estas palavras, em honra a Deus e a Sua bendita Mãe, que a nós nesse século nos fizera tanta honraria e ajuda e, em remissão de nossos pecados e na presença de todos os ricos-homens, dos cavaleiros e cidadãos, renunciamos em poder do dito nosso filho, o infante Dom Pedro, ao qual tornamos herdeiro de todos os nossos reinos e toda a nossa terra. Assim, vestimos o hábito de Cister e nos fizemos monge daquela ordem. E o dito filho nosso, para cumprir o mandamento que nós fizéramos, se despediu de nós e de todos os ricos-homens e cavaleiros com muitos prantos e muitas lágrimas, e em seguida partiu para Játiva para guarnecer a fronteira. ${ }^{47}$

Comparando os dois documentos que contêm o mesmo assunto, o detalhe que se destaca no testamento contido no Livro dos Feitos (documento acima) refere-se à disposição de que o infante Pedro seria o único herdeiro de toda Coroa; além disso, sobre este assunto não há nenhuma citação do infante Jaime. Mas, qual seria o motivo desta diferença entre os dois documentos?

É correto que o infante Jaime, aquele que seria Jaime II de Maiorca, fora jurado como herdeiro deste reino em 1256 e desde agosto de 1257 recebera uma autorização de seu pai, Jaime I, o qual lhe estabelecera como procurador do reino de Maiorca em um contexto em que o processo de colonização e organização da ilha ainda não terminara ${ }^{48}$ Entretanto, apesar dos compromissos assumidos, isso não seria o motivo para que não estivesse presente juntamente 
com seu irmão Pedro no final da narrativa do manuscrito de Poblet referente ao testamento de seu pai.

Analisamos, então, a narrativa do manuscrito de 1343 a partir do outro contexto, ou seja, o contexto de composição. Recordamos: o testamento de Jaime I - originalmente composto em 1272 - é uma cópia de 1349; o testamento do manuscrito de Poblet fora composto no momento da confiscação de Maiorca feita pelo Cerimonioso (1343). Desta forma, a parte final da narrativa do manuscrito de Poblet tem um significado quando relacionada ao momento da composição do mesmo, já que a frase "renunciamos em poder do dito nosso filho, o infante Dom Pedro, ao qual tornamos herdeiro de todos os nossos reinos e toda a nossa terra", relaciona-se mais com o momento de produção do manuscrito em 1343 que com o contexto do final do reinado de Jaime I. Neste sentido, a frase destacada acima confirmaria toda a política de confiscação dos territórios da Coroa de Maiorca por parte dos reis da Coroa de Aragão, desde Pedro o Grande até Pedro o Cerimonioso, e ajudaria a este rei a confirmar as suas intenções na formação territorial da Coroa de Aragão por meio da confiscação de diversos territórios.

Outra observação reforça ainda mais o significado da narrativa relacionada ao contexto de composição do manuscrito: a cópia mais antiga em latim do Livro dos Feitos (Liber Gestarum - ms. 64 Biblioteca da Universitat de Barcelona) é de 1313 e não contém os últimos fólios, os quais provavelmente comentariam sobre o testamento do Conquistador ${ }^{49}$; portanto, o documento mais antigo sobre o testamento do Conquistador existente é o manuscrito de Poblet. Neste sentido, podemos afirmar que foi com a intenção de recordar um passado específico de sua dinastia que o Cerimonioso fez com que a nova cópia do Livro dos Feitos participasse na confiscação da Coroa de Maiorca, fato que confirma a relação estabelecida por este monarca entre o poder do passado e a escrita e sua utilização em um contexto específico.

Como comentamos anteriormente, Pedro o Cerimonioso fora um rei preocupado com a memória histórica de seus antepassados. Mesmo patrocinando uma cópia do Livro dos Feitos de Jaime I nos anos iniciais de seu reinado com a intenção de que a mesma participasse ativamente no processo de reincorporação da Coroa de Maiorca à Coroa de Aragão, o rei, anos mais tarde, patrocinara outra cópia deste mesmo documento, a qual atualmente encontra-se na Biblioteca de Catalunya, em Barcelona, sob o registro 1734.

\section{O MS. 1734 DA BIBLIOTECA DE CATALUNYA}

O outro manuscrito do Livro dos Feitos composto durante o reinado de Pedro o Cerimonioso é conhecido como manuscrito de Aiamans, o ms. 1734 da Biblioteca de Catalunya. Em seu conteúdo encontram-se as mesmas 
informações textuais que o manuscrito de Poblet, embora a numeração dos capítulos seja diferente. Entretanto, em seu colofão encontramos a seguinte informação:

Ordenado pelo sereníssimo senhor Pedro, pela graça de Deus rei de Aragão, Valência, Maiorca, Sardenha e Córsega, conde de Barcelona, de Rossilhão e de Cerdanha, com cujo caráter, pela graça de Deus, prendeu o cruel Pedro, rei de Castela, o qual foi dilacerado por uma espada em seu próprio reino durante a guerra entre os mesmos reis, e o reino regressou às mãos do ilustre Enrique, que posteriormente foi rei de Castela. Eu, João de Barbastro, [...] na cidade de Barcelona, no ano do nascimento do senhor $1380 .{ }^{50}$

Pelos dados observados, o ano da composição deste códice foi 1380 e seu patrocinador foi o rei Pedro o Cerimonioso. Além disso, há uma informação que se refere a um dos acontecimentos mais conhecidos do reinado deste rei e que fora narrado em sua Crônica: trata-se da Guerra dos dois Pedros (13561369) ocorrida entre o rei da Coroa de Aragão e Pedro I de Castela (13501369). Dessa forma, ao contrário do que fizemos anteriormente, devemos analisar não somente o contexto de composição (ano de 1380), mas também o contexto de referência encontrado no colofão do manuscrito (1356-1369) e representado pela Guerra dos dois Pedros para encontrar sua relação com a formação territorial da Coroa de Aragão.

De acordo com o sexto capítulo da Crônica do Cerimonioso, o rei Pedro I de Castela acusava alguns funcionários da Coroa de Aragão de sequestrarem navios genoveses que estavam sob a sua proteção, fato que teve como consequência o rompimento diplomático entre os dois reis. Este fato iniciou uma guerra que teve como resultado a morte do rei castelhano e a subida de Enrique II de Trastâmara (1369-1379) ao trono de Castela ${ }^{51}$ como consta no colofão apresentado.

$\mathrm{Na}$ fase inicial da guerra ocorrera somente troca de cartas entre os reis acusando-se mutuamente e também rompimentos diplomáticos e declarações de guerra relacionadas com o aprisionamento dos $\operatorname{barcos}^{52}$, fato que ocorria frequentemente entre as coroas ibéricas. ${ }^{53}$ Seis meses depois do início da guerra as acusações entre os monarcas esclareceram-se como afirma o Cerimonioso em sua Crônica: a queixa específica do rei castelhano se relacionava às terras do reino de Múrcia, as quais foram perdidas para a Coroa de Aragão anos antes. ${ }^{54}$

A disputa pelo território de Múrcia pelos monarcas das coroas de Aragão e Castela remonta à guerra entre Jaime II de Aragão o Justo (1291-1327) e Fernando IV de Castela (1295-1312) entre os anos de 1296 e 1304, quando a Coroa de Castela perdera a parte setentrional de Múrcia para a Coroa de Aragão. Desta forma, seguindo a narrativa das memórias do Cerimonioso, o 
aprisionamento dos barcos castelhanos não fora o motivo principal da Guerra dos dois Pedros como afirmam alguns autores ${ }^{55}$, principalmente porque na narrativa da Crônica do Cerimonioso o rei castelhano afirmou que desejava saber mais detalhes sobre as terras do reino de Múrcia. Analisado desde esta perspectiva, este acontecimento fora motivado pelo rei castelhano com a intenção de conseguir um acesso ao mar Mediterrâneo.

Analisando esta informação e a declaração do Cerimonioso vista anteriormente, qual seria o interesse do rei castelhano nas terras do reino de Múrcia? Uma provável resposta pode ser encontrada na Crônica de Ramon Muntaner (1265-1336) ${ }^{56}$ De acordo com este documento, a guerra pelo reino de Múrcia entre Jaime II, rei da Coroa de Aragão, e Fernando IV, rei de Castela, ocorreu quando o pretendente ao trono castelhano, Afonso da Cerda (12701333) ofereceu esta Coroa ao rei Jaime II em troca de sua ajuda para conseguir o trono castelhano no exato momento da morte do rei de Castela Sancho o Bravo (1284-1295), no dia 25 de abril de 1295. Esta campanha que o rei da Coroa de Aragão dirigiu pessoalmente ocorreu entre os dias 22 de abril e 28 de junho de 1296, cujo resultado final fora o tratado estabelecido entre Jaime II e João Manuel (1282-1348), o qual definia que quando este completasse 20 anos de idade as terras que então pertenciam ao rei lhe seriam entregues e, em troca, reconheceria a Jaime II como soberano deste reino. ${ }^{57}$

Passados os primeiros momentos da Guerra dos dois Pedros, as duas partes estabeleceram uma trégua em maio de 1357, fato que possibilitou ao rei de Aragão reforçar suas fronteiras e solicitar ao infante Fernando (1329-1363), marquês de Tortosa, que permanecesse na Coroa de Aragão para ajudar na defesa do território. Enquanto que o rei de Aragão comunicou-se com diferentes lugares de sua Coroa, organizando as despesas e os assuntos referentes às tréguas, seu irmão, o infante Dom Fernando, procurador geral da Coroa, solicitou ao rei castelhano que lhe devolvesse a vila de Jumela; entretanto, não obteve sucesso em sua solicitação e Pedro I não lhe devolvera este território. Diante desta situação, o infante invadiu o reino de Múrcia com as hostes de Valência, episódio que provocou a morte do infante João pelo rei castelhano, o qual era irmão do infante Dom Fernando e do rei Pedro o Cerimonioso. ${ }^{58}$

Analisando a sequência dos acontecimentos (solicitação da vila de Jumela; recusa do rei castelhano; invasão das terras do reino de Múrcia; assassinato do infante João; quebra da trégua) fica claro que o motivo do rompimento dos pactos fora o ataque de Pedro I de Castela ao infante João. Ademais, nesta parte da narrativa não há nenhum comentário sobre a invasão de Múrcia realizada durante as tréguas estabelecidas pelo infante Fernando, sendo, portanto, muito provável que a invasão às mesmas ocorrera porque não estavam relacionadas à trégua estabelecida. ${ }^{59}$ Dessa forma, como a Crônica é um documento que fora composto sob o patrocínio do Cerimonioso, podemos afirmar que a mesma reflete seu pensamento acerca das terras deste reino: a 
invasão deste território pelo infante Fernando não supunha nada grave para a trégua que naquele momento existia entre as duas coroas.

Esta reflexão confirma nossa hipótese sobre o motivo da Guerra dos dois Pedros: ou seja, as disputas pelas terras de Múrcia entre as coroas de Aragão e Castela. Para Pedro o Cerimonioso, as terras de Múrcia não estavam relacionadas à trégua estabelecida naquele momento; por outro lado, para Pedro I este era o motivo principal de toda a disputa entre as coroas. Como já destacamos, lendo a narrativa da Crônica do Cerimonioso parece estranha a afirmação de que a prisão dos barcos castelhanos fora o motivo principal desta guerra; ademais, o interesse do rei Pedro I nas informações sobre as terras de Múrcia nos faz suspeitar, já que o que aconteceu inicialmente entre os reis foi um incidente marítimo.

Devido à influência da Guerra dos dois Pedros sobre a Coroa de Aragão, Pedro o Cerimonioso decidira entregar o comando da guerra ao seu aliado, Enrique II de Trastâmara, o qual desejava o trono castelhano. Após diversas batalhas, Enrique II ainda sofrera uma última derrota na batalha de Nájera em 3 de abril de 1367. Ramon d'Abadal recorda que naquele momento o Cerimonioso se equivocou ao anular os tratados com Enrique II de Trastâmara ${ }^{60}$, já que em 1369 este se tornava definitivamente rei de Castela, quando ele e os seus cavaleiros mataram o protagonista castelhano da Guerra dos dois Pedros, ou seja, Pedro I de Castela.

Este é o ano de 1369, último e decisivo para a guerra entre Aragão e Castela. Depois da vitória definitiva contra o rei castelhano, o rei Enrique II solicitou ao Cerimonioso que o casamento entre seus filhos se realizasse, o qual, devido à Guerra dos dois Pedros, não ocorrera, já que o rei Pedro I fez a sua última tentativa de retornar ao trono de Castela em 1369.

Após nos aproximarmos do contexto a que o colofão do manuscrito de Aiamans faz referência, ou seja, a Guerra dos dois Pedros, devemos estabelecer a relação entre este e o contexto de composição do manuscrito (1380). Neste sentido, a Crônica de Pedro o Cerimonioso fornece informações centrais sobre o desenrolar dos acontecimentos após esta guerra. A primeira se refere à entrega de alguns lugares que deveria ser realizada pelo novo rei castelhano, Enrique II de Trastâmara, ao Cerimonioso, feito que não ocorrera; por outro lado, o rei Enrique fez um pagamento ao rei aragonês sobre estas terras. ${ }^{61} \mathrm{~A}$ segunda informação se refere ao envio da infanta Eleonor de Aragão para que o casamento com o filho do rei castelhano, o infante João, se realizasse. Porém, o Cerimonioso não desejava enviar a dita infanta porque solicitara ao rei castelhano que primeiro cumprisse com "certas conveniências" como rei de Castela, as quais eram a entrega de "muitos e diversos lugares" e "alguns outros lugares" na fronteira entre Castela e Aragão. Tanto o pagamento quanto o casamento ocorreram em 1375; já a entrega das localidades entre Castela e Aragão, não. ${ }^{62}$ 
Neste mesmo ano fora assinado um tratado entre o Cerimonioso e Enrique de Trastâmara: trata-se do Tratado de Almazá, o qual anulava todo o passado referente às disputas das terras de Múrcia entre as casas de Aragão e Castela ${ }^{63}$, representando um acordo de paz estabelecido entre os reis de Aragão e Castela logo após a Guerra dos dois Pedros. Analisando o documento observamos que há seis pontos principais: 1) o estabelecimento da paz entre os reis das duas coroas e a extensão do mesmo aos seus respectivos descendentes; 2) a anulação da autorização da passagem de inimigos da Coroa de Castela pelas terras da Coroa de Aragão; 3) a concessão da licença aos cavaleiros da Coroa de Aragão para servirem ao rei de Castela; 4) o estabelecimento do matrimônio entre a infanta Eleonor de Aragão e o infante João de Castela; 5) a devolução da vila e condado de Molina com os seus territórios ao rei de Aragão e 6) a renúncia por parte do rei de Aragão, assim como seus sucessores e antepassados, às solicitações, demandas e outros documentos estabelecidos e elaborados no passado, ademais da entrega da documentação originada destes pactos.

Esta última informação é que mais nos interessa para nos aproximarmos do significado histórico do ms. 1734 da Biblioteca de Catalunya. Sabemos que ocorreram pactos entre as coroas de Castela e Aragão referente à demarcação de territórios entre os séculos XII e XIII (como o Tratado de Tudela - 1151; o Tratado de Cazola - 1179; o Tratado de Almisrà - 1244), tratados diretamente relacionados ao desenvolvimento da Reconquista na Península Ibérica. Considerando estas delimitações, o Tratado de Almazá anulava todas as disputas territoriais entre as duas coroas já que o mesmo continha esta cláusula retroativa que fazia referência aos antecessores dos monarcas que então reinavam em cada coroa (ponto 6 do parágrafo anterior).

Entretanto, devemos nos questionar sobre o motivo do estabelecimento de um tratado entre as duas coroas no ano de 1375. Buscando uma resposta na narrativa da Crônica de Pedro o Cerimonioso observamos que há uma omissão de seis anos na narrativa deste documento, uma lacuna entre 1369 e 1375. Ferran Soldevila, em sua edição comentada das Quatro Grandes Crônicas, já advertira que o Cerimonioso omitira as informações destes anos em sua Crônica. ${ }^{64}$ Trata-se, assim, da omissão de um período, comentário que considerando o teor do Tratado de Almazá confirmaria a continuidade da insistência de Pedro o Cerimonioso em obter as terras do reino de Múrcia. Como vimos na solicitação feita pelo Cerimonioso ao rei Enrique II, alguns lugares lhe foram entregues; entretanto, a solicitação mais importante, o reino de Múrcia, território que o novo rei castelhano deveria retornar ao Cerimonioso de acordo com os tratados estabelecidos em Perpinyà e em Monzón no ano de $1363^{65}$, não lhe fora retornado.

Considerando as questões que aqui estudamos, parece que o Cerimonioso omitira esta guerra em sua Crônica e a substituíra externamente pela solicitação da cópia do Livro dos Feitos de Jaime I de 1380; omitira a vergonha de uma 
derrota e recordara a vitória de seu tataravô e a ajuda do mesmo ao rei castelhano Afonso X o Sábio, em 1266, contida na narrativa desta cópia; não mencionou a derrota diante de seu inimigo e a substituíra por um objeto da cultura escrita dos condes de Barcelona e reis de Aragão que representava a vitória definitiva de Jaime I o Conquistador naquelas terras. Ademais, de acordo com Ramon d'Abadal, depois do Tratado de Almazá as ilusões do rei de Aragão pelas terras do reino de Múrcia acabaram-se, o que significou o final do duelo bélico entre Castela e Aragão. ${ }^{66}$

Além disso, devemos recordar três questões que confirmam o provável envio deste documento ao rei de Castela, João I (1379-1390), que também era genro de Pedro o Cerimonioso. A primeira é que a Guerra dos dois Pedros promoveu grandes despesas para a Coroa de Aragão, a qual sofrera financeiramente com a mesma, já que não resultou em compensações econômicas nem territoriais e, além disso, contribuiu para o empobrecimento da mesma durante o reinado do Cerimonioso.$^{67}$ Em segundo lugar o rei João I, neto do Cerimonioso, logo após o início de seu reinado estabelecera juízes para que delimitassem as fronteiras entre Oriola e Múrcia, provavelmente com a intenção de resolver a situação territorial com a Coroa de Aragão ${ }^{68}$; diante desta situação, fica claro que o Cerimonioso, logo no início do reinado de João I, ainda perseverava na resolução deste assunto. Em terceiro lugar, devemos recordar a situação da Coroa de Aragão no final do reinado do Cerimonioso (a questão demográfica; a dívida da Coroa e o aumento cada vez maior do poder das Cortes) ${ }^{69}$ Desta forma, a solução encontrada pelo rei aragonês fora a utilização de uma estratégia a qual desenvolvera durante o seu reinado: a escrita.

\section{CONCLUSÃO: PEDRO O CERIMONIOSO E A UTILIZAÇÃO DO PASSADO PARAA CONSTRUÇÃO TERRITORIAL}

A produção dos dois primeiros manuscritos da tradição catalã do Livro dos Feitos fornece um exemplo de como o passado fora utilizado na Coroa de Aragão, especificamente no caso de Pedro o Cerimonioso, patrocinador dos códices. No que se refere à dinastia a qual fazia parte, é correto que este rei privilegiou os aspectos políticos de seu tataravô, Jaime I, já que a Crônica do seu reinado fora composta como um ato imitador do Livro dos Feitos. Nos dois casos analisados podemos afirmar que o Cerimonioso necessitava da presença da auctoritas de seu antepassado para utilizá-la em seu presente. Neste sentido, devemos perceber os níveis de utilização do passado empreendidos por este monarca no caso das cópias do Livro dos Feitos.

No que se refere ao primeiro manuscrito, composto em 1343, observamos que o ato de sua composição completara a ação militar empreendida pelo Cerimonioso na confiscação da Coroa de Maiorca quando esta fora anexada à 
Coroa de Aragão. Portanto, ao mesmo tempo em que realizou uma ação militar Pedro o Cerimonioso também se preocupou com o passado modificando-o no Livro dos Feitos e anulando a criação da Coroa de Maiorca por parte de Jaime I o Conquistador.

Diante destas constatações, fora com a intenção de fazer com que o passado histórico do reinado de Jaime I estivesse presente em um contexto específico que o Cerimonioso fez com que a sua cópia do Livro dos Feitos participasse textualmente concomitantemente à extinção militar da Coroa de Maiorca. Dessa forma, toda a política dos condes de Barcelona e reis de Aragão que estiveram contra a Coroa de Maiorca era legitimada, fato que fica claro na leitura do testamento de Jaime I contido no Livro dos Feitos, onde este monarca estabelecera como único herdeiro de suas terras seu filho Pedro o Grande.

No caso do manuscrito de Aiamans, elaboramos algumas conclusões sobre as razões pelas quais o Cerimonioso solicitara esta cópia. Em primeiro lugar para recordar uma vez mais o seu tataravô, o rei Jaime I, o qual conquistara definitivamente o reino de Múrcia diante dos muçulmanos. Com esta ação o rei da Coroa de Aragão desejava que o novo rei castelhano, ou seja, João I, soubesse que a verdadeira conquista do reino de Múrcia fora realizada por um rei da dinastia dos condes de Barcelona e reis de Aragão. Segunda: recordar a ajuda de Jaime I ao rei castelhano Afonso o Sábio na conquista de Múrcia em 1266. Esta ajuda, documentada com detalhes no Livro dos Feitos, fora um ponto importante nas relações entre os reis das coroas de Aragão e Castela. Ademais, a comunicação entre estes dois monarcas no Livro dos Feitos demonstra que as negociações entre os mesmos, depois da ajuda aos castelhanos em Múrcia em 1266, foram decisivas para aproximar politicamente as duas potências peninsulares. Terceira: a recordação da conquista do reino de Múrcia realizada por um antepassado fora a última tentativa por parte do Cerimonioso em recuperar as terras perdidas nas disputas entre as duas coroas, não mais no campo bélico, mas sim no literário.

Considerados em suas particularidades e contextualizados em seus momentos de composição, estes objetos transformavam-se em instrumentos de poder: se inicialmente continham informações sobre a vida de um antepassado de Pedro o Cerimonioso, a partir da análise das suas particularidades tornaramse artefatos simbólicos e referenciais onde o passado adquiria significado e poderia ser utilizado no âmbito historiográfico.

Temos, então, dois exemplos de como a construção e a recordação do passado fora feita pelo rei Pedro o Cerimonioso e como esta influenciou na formação territorial da Coroa de Aragão, tanto na confiscação da Coroa de Maiorca quanto no estabelecimento das fronteiras com o reino de Múrcia. Desde esta perspectiva, percebe-se a importância do passado para o rei Pedro o Cerimonioso, principalmente respeito à formação territorial de sua Coroa: para ele, o tempo pretérito era um mundo no qual poderia encontrar as respostas para os seus problemas contemporâneos e materializá-lo através de um objeto. 


\section{NOTAS}

${ }^{1}$ SPIEGEL, Gabrielle M. Political utility in medieval historiography: a sketch. History and Theory, n. 3, v. 14, p. 314-325, 1975.

2 DAGENAIS, John. The Ethics of Reading in Manuscript Culture. Princeton: Princeton University Press, 1994. p. 217-218.

${ }^{3}$ SPIEGEL, Gabrielle M. History, Historicism and the Social Logic of the text. In: The past as text: the theory and practice of medieval historiography. Baltimore and London: The Johns Hopkins University Press, 1997. p. 3-28.

${ }^{4}$ AURELL, Jaume. El Nuevo Medievalismo y la interpretación de los textos históricos. HISPANIA. Revista Española de Historia, n. 224 (septiembre-diciembre), v. LXVI, p. 809-832, 2006.

${ }^{5}$ ELIZONDO, Maria Teresa Echenique. Comentario Filológico de un texto castellano medieval. In: El análisis textual. Comentario filológico, literario, lingüístico, sociolingüístico y crítico. Salamanca: Ediciones Colegio de España, 1997. p. 9-28.

${ }^{6}$ ALTURO I PERUCHO. Jesús. Història del llibre manuscrit a Catalunya. Barcelona: Generalitat de Catalunya, 2003. p. 250-257.

7 VIANNA, Luciano J. Methodological Approaches to Cultural History: Studies and Applications - The Book as an Object of the Political Cultural Behavior. London, 84 p. Programme of Grants for Research Stays Abroad (BE-DGR 2011), from the AGAUR (Agència de Gestió d'Ajuts Universitaris i de Recerca), from the Catalan Government (Spain), resolution ECO/1698/2011, of 28 of June (DOGC no. 5918 of 12.7.2011).

${ }^{8}$ MARTINES, Vicent. L'edició filologica de textos. València: Publicacions de la Universitat de València, 1999. p. 27.

9 As Quatro Grandes Crônicas são: o Livro dos Feitos, a Crônica de Bernat Desclot, a Crônica de Ramon Muntaner e a Crônica de Pedro o Cerimonioso. Sobre os textos editados destas crônicas ver Les Quatre Grans Cròniques. Revisió del text, pròlegs i notes per Ferran Soldevila. Barcelona: Editorial Selecta, 1971. Sobre os últimos estudos realizados sobre estas crônicas ver CINGOLANI, Stefano. La memòria dels reis. Les Quatre Grans Cròniques. Barcelona: Editorial Base, 2008 e AURELL, Jaume. Authoring the Past. History, Autobiography, and Politics in Medieval Catalonia. Chicago and London: The University of Chicago Press, 2012.

${ }^{10}$ Les Quatre Grans Cròniques, op. cit.

${ }^{11}$ Llibre dels fets del rei en Jaume (A cura de Jordi Bruguera). Collecció Els nostres clàssics, B 10-11, 2 v. Barcelona: Editorial Barcino, 1991.

${ }^{12}$ MARTÍNEZ SAN PEDRO, Maria de los Desamparados. La Crónica Latina de Jaime I. Edición crítica, estudio preliminar e índices. Almería: Gráficas Ortiz, 1984. Atualmente o prof. Antoni Biosca i Bas da Universitat d'Alacant prepara uma nova edição crítica do Liber Gestorum.

${ }^{13}$ Llibre dels fets del rei en Jaume (A cura de Jordi Bruguera), op. cit.

${ }^{14}$ MARTÍNEZ SAN PEDRO, op. cit.

${ }^{15}$ STRAYER, Joseph R. Sobre los origenes medievales del estado moderno. Barcelona: Ariel, 1981. p. 79-120.

${ }^{16}$ BAYONA AZNAR, Bernardo. El origen del Estado laico desde la Edad Media. Madrid: Editorial Tecnos, 2009. 
${ }^{17}$ GIMENO BLAY, Francisco M. Produir llibres manuscrits catalans (segles XII-XV). In: BADIA, Lola; CABRÉ, Mirian; MARTÍ, Sadurní. Literatura i cultura a la corona d'Aragó (S. XIII-XV) - Textos i estudis de cultura catalana. Barcelona: Publicacions de l'Abadia de Montserrat, 2002. p. 115-141.

${ }^{18}$ PETRUCCI, Armando. Prólogo. In: GIMENO BLAY, Francisco M. Escribir, Reinar: La experiencia gráfico-textual de Pedro IV el Ceremonioso. Madrid: Abada Editores, 2006. p. 13.

${ }^{19}$ CACHO BLECUA, Juan Manuel. Traducciones catalanas y aragonesas en el entorno de Juan Fernández de Heredia. In: BADIA, Lola; CABRÉ, Mirian; MARTÍ, Sadurní. Literatura i cultura a la corona d'Aragó (S. XIII-XV), op. cit., p. 299-318.

${ }^{20}$ RUBIÓ I BALAGUER. Jordi. Història i historiografia. Barcelona: Departament de Cultura de la Generalitat de Catalunya; Publicacions de l'Abadia de Montserrat, 1987. p. 427.

${ }^{21}$ GIMENO BLAY, 2006, op. cit., p. 22.

${ }^{22}$ Ibidem, p. 157.

${ }^{23}$ GIMENO BLAY, 2002, op. cit., p. 115-141.

${ }^{24}$ GIMENO BLAY, 2006, op. cit., p. 145.

${ }^{25}$ TASIS I MARCA, Rafael. El segle XIV - Pere el Cerimoniós i els seus fills. In: Història de Catalunya - IV. Barcelona: Cupsa Editorial Planenta S. A., 1979. p. 7-215.

${ }^{26}$ GIMENO BLAY, 2006, op. cit., p. 149-156.

${ }^{27}$ Por exemplo, o documento a seguir demonstra o contato entre o rei e o copista Bernat Dezcoll e é uma das comprovações da intervenção real no processo de composição de sua Crônica: "En Bernat Dezcoll: vostra letra havem reebuda e responem vos que tenim per bons lo primer, segon e terç capítols de les cròniques; però que u façats per menut al mes que porets". Documents per l'historia de la cultura catalana mig-eval. Vol. I. Publicats per Antoni Rubió i Lluch. Barcelona: Institut d'Estudis Catalans, 2000, p. 263 (document CCLXXXIII).

${ }^{28}$ Esta parte contém os resultados da minha dissertação de mestrado apresentada no Departament de Ciències de l'Antiguitat i de l'Edat Mitjana da Universitat Autònoma de Barcelona, e que recebeu em abril de 2011 o prêmio da Societat Catalana d'Estudis Històrics (SCEH), evento organizado pelo Institut d'Estudis Catalans (IEC).

${ }^{29}$ D'ABADAL, Ramon. Pere el Cerimoniós i els inicis de la decadència política de Catalunya. Barcelona: Edicions 62, 1987. p. 285.

${ }^{30}$ Documents per l'historia de la cultura catalana mig-eval. v. I, op. cit., p. 128 (Documento CXVII).

${ }^{31}$ Biblioteca da Universitat de Barcelona, ms. 1, fol. $201 \mathrm{r}$.

32 "Neste domingo, à hora primeira, nós ainda não havíamos levantado e líamos o livro ou Crônica do senhor rei Dom Jaime, nosso tataravô". Crònica de Pere el Cerimoniós. In: Les Quatre Grans Cròniques, op. cit., p. 1086.

${ }^{33}$ GIMENO BLAY, 2006, op. cit., p. 172.

${ }^{34}$ Raimundo Berengário IV não intitulou-se rei de Aragão, mas sim príncipe de Aragão. MORALES I MONTOYA, Mercè e SOBREQUÉS I CALLICÓ, Jaume. Comtes, reis, comtesses $i$ reines de Catalunya. Barcelona, Editorial Base, 2011. p. 72-75.

${ }^{35}$ AURELL, Martin. Les Noces du comte. Mariage et pouvoir en Catalogne (785-1213). Paris: Publications de la Sorbonne, 1995. 
${ }^{36}$ BALCELLS, Albert. Història de Catalunya. Barcelona: L'esfera dels llibres, 2004.

${ }^{37}$ RUCQUOI, Adeline. Histoire médiévale de la Péninsule Ibérique. Paris: Éditions du Seuil, 1993.

${ }^{38}$ SPIEGEL, Gabrielle M. Romancing the Past: the rise of vernacular prose historiography in thirteenth-century France. Berkeley/Los Angeles/London: University of California Press, 1995. p. 4.

${ }^{39}$ Crònica de Pere el Cerimoniós, op. cit., p. 1023, 1036 e 1037.

${ }^{40}$ MARTÍNEZ FERRANDO. J. E. La trágica storia dei re di Maiorca. Cagliari: Edizioni dell'Istituto sui Rapporti Italo-Iberici, 1993.

${ }^{41}$ Crònica de Pere el Cerimoniós, op. cit., p. 1037.

${ }^{42}$ MARTÍNEZ FERRANDO, op. cit.

${ }^{43}$ PUJOL, Gabriel Ensenyat. La reintegració de la Corona de Mallorca a la Corona d'Aragó (1343-1349) I. Mallorca: Editorial Moll, 1997. p. 90-93.

${ }^{44}$ Ibidem, p. 102.

${ }^{45}$ UDINA I ABELLÓ, Antoni. Els testaments dels comtes de Barcelona i dels reis de la Corona d'Aragó. De Guifré Borrell a Joan II. Barcelona: Fundació Noguera - Col·lecció Textos i Documents, 2001. p. 147-148 (a tradução é minha).

${ }^{46}$ CINGOLANI, Stefano. Historia y mito del rey Jaime I de Aragón. Barcelona: Edicions 62, 2008. p. 36-37.

${ }^{47}$ Biblioteca da Universitat de Barcelona, ms. 1, fol. 200v-201r. Livro dos Feitos. Tradução e notas de Luciano José Vianna e Ricardo da Costa. São Paulo: Instituto Brasileiro de Filosofia e Ciência Raimundo Lúlio (Ramon Llull), 2010. p. 479-480.

${ }^{48}$ BENNÀSSER, Pau Cateura. Jaume I: conquesta i organització del regne de Mallorca. In: $E l$ rei Jaume I: fets, actes i paraules. COLÓN DOMÈNECH, Germá; MARTÍNEZ ROMERO, Tomàs (Eds.). Castelló: Fundació Germà Colón Domènech; Barcelona: Publicacions de l'Abadia de Montserrat, 2008. p. 33-51.

${ }^{49}$ MARTÍNEZ SAN PEDRO, op. cit., p. 401.

${ }^{50}$ Biblioteca de Catalunya, ms. 1734, f. 157 (a tradução é minha).

${ }^{51}$ BARUQUE, Julio Valdeón. Los Trastáramas. El triunfo de una dinastía bastarda. Madrid: Ediciones Temas de Hoy, 2001.

${ }^{52}$ Crònica de Pere el Cerimoniós, op. cit., p. 1125, 1127, 1129, 1130, 1132.

${ }^{53}$ MUTGÉ I VIVES, Josefina. Activitat piràtica entre catalano-aragonesos i castellans a la mediterrània occidental durant el regnat de Jaume II. Anales de la Universidad de Alicante. Historia Medieval, n. 11, p. 445-456, 1996-1997.

${ }^{54}$ Crònica de Pere el Cerimoniós, op. cit., pp. 1132-1133.

${ }^{55}$ MALDONADO Y COCAT, Ramón José. La Rioja en la Guerra Civil entre D. Pedro el Cruel y D. Enrique de Trastámara (Las batallas de Nájera). Berceo. Revista Riojana de Ciencias Sociales y Humanidades, n. 10, p. 61-82, 1949; FERRER I MALLOL, Maria Teresa. La frontera meridional valenciana durant la guerra amb Castella dita dels Dos Peres. In: Pere el Cerimoniós i la seva època. Barcelona: Consell Superior d'Investigacions Científiques. Institució Milà i Fontanals. Unitat d'Investigació d'Estudis Medievals, 1989. p. 245-357; MUÑOZ POMER, María Rosa. Preliminares de la guerra de los dos Pedros en el reino de 
Valencia (1356). Anales de la Universidad de Alicante. Historia Medieval, n. 1, p. 117-134, 1982; BISSON, T. N. Història de la Corona d'Aragó a l'Edat Mitjana. Barcelona: Editorial Crítica, 1988; VALDEÓN, Julio. Pedro I el Cruel y Enrique de Trastámara. ¿La primera guerra civil española? Madrid: Santillana Ediciones Generales, S. L., 2002.

${ }^{56}$ Crònica de Ramon Muntaner. In: Les Quatre Grans Cròniques, op. cit., p. 886-887.

${ }^{57}$ MASIÁ DE ROS, Ángeles. Relación castellano-aragonesa desde Jaime II a Pedro el Ceremonioso. v. I. Barcelona: Consejo Superior de Investigaciones Científicas, 1994. p. 67-69.

${ }^{58}$ Crònica de Pere el Cerimoniós, op. cit., p. 1134.

${ }^{59}$ BISSON, op. cit., p. 123.

${ }^{60}$ D'ABADAL, op. cit., p. 208.

${ }^{61}$ Deste documento podemos retirar algumas informações: podemos afirmar que o rei castelhano pagaria uma quantia de maravedís aos reis de Aragão e Navarra, a qual depois recuperaria das cidades, vilas, aljamas e morarias do reino mediante o seu funcionário Samuel Abraulla. Ademais, o documento nos chama a atenção quando comenta o valor estipulado a ser pago pela cidade de Múrcia: 1250 maravedis, o qual em comparação com outras cidades era elevado. Diante desta informação, a suposição mais racional é que esta solicitação financeira foi alta para a cidade de Múrcia por causa da intenção do Cerimonioso em recuperar este reino juntamente ao rei de Castela. Este, em troca, pagaria ao rei aragonês pela cidade, e esta "retornaria" o dinheiro ao rei castelhano. Colección de documentos para la historia del reino de Múrcia. Vol VIII. Documentos de Enrique II. Edición de MARTÍNEZ, Lope Pascual. Múrcia: Academia Alfonso X, el Sabio; Consejo Superior de Investigaciones Científicas, 1983. p. 299-301 (Documento 189).

${ }^{62}$ Crònica de Pere el Cerimoniós, op. cit., p. 1153.

${ }^{63}$ MASIÁ DE ROS, op. cit., p. 599-604.

${ }^{64}$ Crònica de Pere el Cerimoniós, op. cit., p. 1222.

${ }^{65}$ VALDEÓN, op. cit., p. 96.

${ }^{66}$ D'ABADAL, op. cit., p. 208, 210.

${ }^{67}$ CINGOLANI, op. cit., p. 234-235; GONZALVO, Julia Campón. Consecuencias de la guerra de los dos Pedros en el condado de Denia. Anales de la Universidad de Alicante. Historia Medieval, n. 08, p. 57-68, 1990-1991.

${ }^{68}$ Colección de documentos para la historia del reino de Múrcia. v. XI. Documentos de Juan I. Edición de MARTÍNEZ; MOLINA MOLINA; RUBIO, op. cit., p. 85-86 e 125 (Documentos 45 e 62 ).

${ }^{69}$ D’ABADAL, op. cit., p. 285-290.

Artigo recebido em setembro de 2012. Aceito em março de 2013. 